\title{
Tag Dosage Form
}

National Cancer Institute

\section{Source}

National Cancer Institute. Tag Dosage Form. NCI Thesaurus. Code C87539.

A pharmaceutical dosage form containing active substance(s) that are delivered via a tag device. 